\title{
Eine neue Gattung der Oxyopisthinen und eine neue Art der Gattung Oxyopisthen (Col.).
}

\author{
Von F. Hartmann in Fahrnau.
}

In der Stett. Ent. Ztg. 1899, pag. 3 u. ff. vereinigt Herr H. J. Kolbe eine Anzahl der bisher zu den Sphenocorynen gestellten afrikanischen Gattungen zu einer neuen Gruppe der Oxyopisthinen und gibt zugleich eine gründliche Bearbeitung der in diese Gruppe gehörenden Gattungen und Arten.

Bei der Sichtung meines Sammlungmateriales nach dieser Bearbeitung finde ich unter demselben zwei Arten, die bisher nicht beschrieben sind, wovon die eine Art einer neuen Gattung angehört.

Scoliopisthen n. g. Oxyo pisthin or um. $\sigma^{x}$ : Rostrum cylindricum, subrectum, subtus longitudinaliter sulcatum, apice subdentatum. Frons tumida et sulcata. Antennae ad latera rostri insertae, subbasales, rostri apicem attingentes. Articulus septimus funiculi elongato-clavatus, apice oblique truncatus, clavam includens. Prothorax supra convexus, basi rotundatus. Scutellum parvum, elongatum. Elytra prothorace aequilata, decemstriata. Femora postica apicem corporis attingentes, mutica, antica mediaqie aequilonga; tibiae rectae, non carinatae. Processus abdominalis latus, obtuse rotundatus. Pygidium valde declivum, longitudinaliter carinatum, carina ante apicem in tuberculum acutum horizontalem excurrens. Articulus quartus tarsorum tertium paullo superans.

Das an den Seiten nicht gekielte Pygidium, der vollständig ausgebildete zehnte Deckenstreif und der gewölbte Halsschild verweisen diese Gattung in die erste Gruppe der Oxy op isthinen, wo sie mit Rücksicht auf die gleich langen Vorder- und Mittelschenkel mit Acherus und Haplorrhynchus, in Bezug auf die andern Merkmale jedoch näher mit Conopisthen verwandt ist, sich von diesem aber hauptsächlich durch die Längenverhältnisse der Vorder- und Mittelschenkel, die ungezähnten, das Körperende erreichenden Hinterschenkel, durch das steil abfallende Pygidium, dann auch auf der Unterseite gefurchten Rüssel und kürzere Fühler unterscheiden lässt.

Scoliopisthen hat wie Conopisthen die aufgetriebene gefurchte Stirn; die Furche setzt sich auf den oben verdickten

Wiener Entomologische Zeitung, XIX. Jahrg., IV. und V. Heft (1. Mai 1900). 
Basaltheil des Rüssels, nicht aber auf diesen selbst, fort. An der Unterseite des Rüssels ist zwischen Basis und Mitte ebenfalls eine Furche eingegraben. Von der Seite gesehen verläuft die Unterkante des cylindrischen Rüssels in fast gerader Linie von der Basis bis zur Spitze, vor welcher ein äusserst kleines Zähnchen bemerkbar ist; die Oberkante geht von der etwas verbreiterten Spitze in sanftem Bogen ansteigend allmälig in den verdickten Basaltheil des Rüssels über, wodurch die Oberseite desselben ausgebuchtet erscheint. Die Fühler erreichen gerade die Rüsselspitze, ihre Einlenkungsstelle liegt etwa um den kleineren Augendurchmesser von dieser entfernt; das erste Geisselglied ist kugelig, das zweite verkehrt kegeltörmig und etwas länger als das erste, das dritte bis sechste quer und dicht aneinander geschlossen; das siebente Glied wie bei Conopisthen gebildet. Der Prothorax ist länger als breit, convex mit feinem Mittelkiel und gerundeter Basis. Schildchen klein und schmal. Flügeldecken nicht breiter als der Halsschild, 10-streifig. Die Vorder- und Mittelschenkel sind einander an Länge gleich, die hintern erreichen die Spitze des Pygidiums, alle sind ungezähnt. Die Schienen aussen nicht gekielt und gerade. Der Abdominalfortsatz ist sehr breit, vorn stumpf abgerundet. Das Pygidium fällt steil nach unten $a b$ und ist in seiner ganzen Länge von einem mehr oder weniger scharfen Kiele durchzogen, der etwas vor der Spitze in ein zahnförmiges, gerade nach hinten gerichtetes Tuberkel ausläuft. Das dritte Tarsenglied ist breit herzförmig und wird nur ein geringes von dem mit verwachsenen Krallen versehenen vierten Gliede überragt.

Scoliopisthen sordidum n. sp. Subcylindricus, totus niger, opacus, undique (rostro elytrisque exceptis) sat dense punctatus; subtus, elytris basi sordide-flavido, thorace supra, elytrorum dimidia parte apicali tomento obscuriore dense tectus. Rostro nitido, laevi, punctis nonnullis subtilissimis disperse obsito; thorace latitudine busali longiore, intra apicem constricto, lateribus medio subsinuato, antrorsum paullo attenuato, angulis posticis rotundatis, dorso medio subtiliter carinato; elytris thorace paullo longioribus, apicem versus sensim parum attenuatis, striatis, in striis disperse punctatis, interstitiis planis, uniseriatim irregulariter punctatis; femoribus subtus, tibiisque nec ciliatis, nec pilosis; segmento primo abdominali late vadoso-foveato. -

L 0 n g.: $8^{1 /}{ }_{2}-9 \mathrm{~mm}, \mathrm{lat}$ t. $2^{1 / 2}-2^{3} / 4 \mathrm{~mm}$.

B enit o, tranzös. Congo. $2 \sigma^{x}$. 
Der ganze Köper des Thieres nebst den Fühlern und Beinen ist ziemlich dicht mässig grob punktirt mit Ausnahme der Decken und des cylindrischen Theiles des Rüssels, welcher glatt und glänzend und nur mit wenigen sehr feinen Punkten bedeckt ist. Jeder Punkt trägt am Grunde ein feines helles Börstchen. Die Streifen der Flügeldecken sind weitläufig punktirt, eine unregelmässige Reihe ebenso gestellter Punkte ist auch auf den flachen Deckenspatien bemerkbar. Die Punktirung des fünften Ventralsegmentes sowie des Pygidiums ist etwas gröber und weniger dicht, die Punkte sind auf dem letzterem mehr in die Länge gezogen und fliessen stellenweise zusammen. Das den Körper bedeckende Toment ist auf der Unterseite und den Beinen schmutzig gelblich, auf dem Pygidium und der Basalhälfte der Decken etwas heller, auf dem Halsschild, der Schulterbeule und der Spitzenhälfte der Flügeldecken dunkelbraun bis schwärzlichbraun. Letztere sind um ein Viertel länger als der Halsschild, der Spitzenrand etwas gerundet und an der Naht stumpfwinkelig ausgeschnitten. Das erste Ventralsegment trägt eine breite, seichte Grube, während das Analsegment ohne weitere Geschlechtsauszeichnung ist. Auf den Vorder- und Mittelschenkeln fehlt jede bürstenartige Bewimperung, dagegen ist auf der Unterseite der Hinterschenkel eine feine, äusserst kurze Börstchenreihe bemerkbar, ausserdem sind die Hinterschenkel unten vor der Spitze etwas ausgerandet.

Oxyopisthen Kolbei n. sp. Oxyop. Westermanni valde affinis; elytris area basali intrahumerali velutinis, thorace vittis duabus lobi abbreviatis, punctiformibus, metasterno linea alba obliqua in $\sigma^{7}$ abbreviata, in of ab medio marginis anterioris ad angulum posticum ducta, tibiis anticis femoribusque maris brevissime ciliatis, ab illo distincte diversus.

o Long.: $17 \frac{1}{2} \mathrm{~mm}$, lat. $5 \mathrm{~mm}$. \& Long.: $19 \mathrm{~mm}$, lat. $5^{1 / 2} \mathrm{~mm}$.

B e n it o, Französ. Congo, ein Pärchen.

Die Bildung des Rüssels in beiden Geschlechtern, ebenso die weisse Zeichnung auf den Seiten des Thorax, der Mittelund Hinterbrust, dem Abdomen und Pygidium entspricht bei der neuen Art dem Ox. Westermanni, sie unterscheidet sich dagegen von diesem in folgenden Punkten: Bei Westermanni bildet die weisse Zeichnung beiderseits neben dem dolchförmigen Scutellarlappen eine theilweise bis zur Spitze desselben rei- 
chende gebogene Binde, während bei Kolbei diese Binde zu zwei kleinen, die Basis des Lappens nicht erreichende weisse Makeln reducirt ist. Die Basis der Decken zwischen der glänzenden Schulterbeule und dem glänzenden ersten und achten Zwischenraum ist in mehr oder weniger grösserer Ausdehnung matt, sammtartig. Auf dem Metasternum zeigt das $q$ eine von der Mitte des Vorderrandes ausgehende, schräg nach dem Hinterwinkel führende, weiss tomentirte Linie, die beim $\sigma^{x}$ ungetähr im vorderen Drittel abgekürzt ist. Der dreieckige Raum zwischen dieser Linie und dem vorderen Metasternalwinkel ist nicht weiss oder gelblich tomentirt wie bei Westermanni, sondern glatt und glänzend und zeigt nur hinter den Mittelhüften eine matte sammetartige Stelle. Erstes Ventralsegment beim $\sigma$ eingedrückt, letztes mit einem länglichen flachen Grübchen; die Vorderschenkel und die Mittelschienen sind äusserst kurz gefranst, entsprechen in dieser Hinsicht dem funebre $\sigma^{\prime}$, während die Befransung der Vorderschienen etwas, aber kaum bemerkbar länger wie bei dieser Art ist. Die männlichen Hinterschenkel unten wie bei Westermanni und funebre bebürstet. Koibei steht demnach durch seine Zeichnung und Rüsselbildung des $\sigma^{\top}$ in naher Beziehung zu Westermanni, dagegen durch die Auszeichnung der männlichen Schenkel und Schienen in Verwandtschaft mit funebre. Die Vorderschienen des of in der Mitte auf der Aussenkante und Innenseite röthlich gefärbt.

Der Scutellarfortsatz ist bei dem mir vorliegenden grösseren o kaum halb so lang als beim $\sigma^{\top}$; ob diese Längendifferenz auch beim Westermanni vorkommt, vermag ich nicht zu entscheiden, da ich von diesem nur $\sigma^{7}$ besitze. Es scheint aber, dass die Länge dieses Gebildes variabel ist, denn bei 11 mir vorliegenden Stücken des funebre finden sich sowohl $\sigma^{7}$ und o mit gleichlangem Fortsatze als auch zwei von Benito, bei welchen dieser Fortsatz des Pronotums beinahe die halbe Flügeldeckenlänge erreicht.

Herrn Kolbe, dem Bearbeiter der Oxyopisthinen-Gruppe, freundlichst gewidmet. 

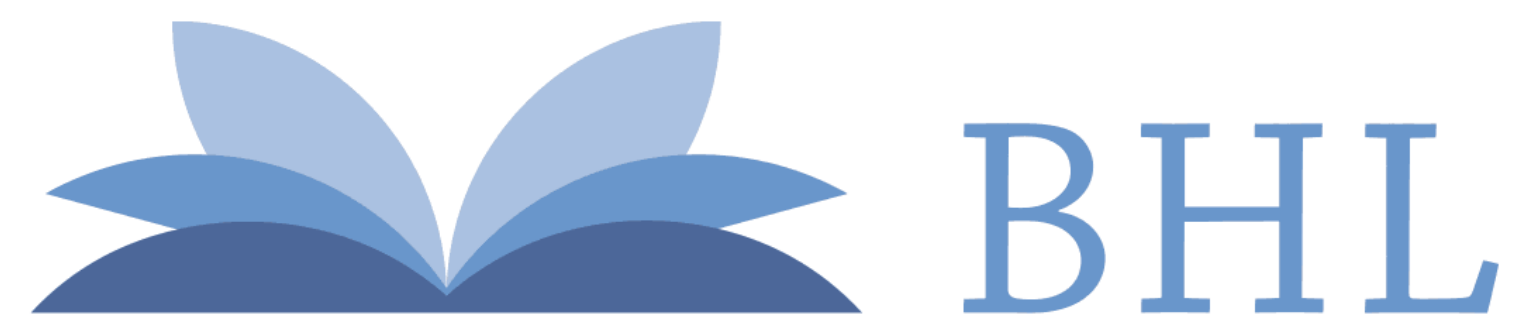

\section{Biodiversity Heritage Library}

Hartmann, Karl Friedrich. 1900. "Eine neue Gattung der Oxyopisthinen und eine neue Art der Gattung Oxyopisthen (Col.)." Wiener entomologische Zeitung 19, 121-124. https://doi.org/10.5962/bhl.part.3443.

View This Item Online: https://www.biodiversitylibrary.org/item/43789

DOI: https://doi.org/10.5962/bhl.part.3443

Permalink: https://www.biodiversitylibrary.org/partpdf/3443

\section{Holding Institution}

Smithsonian Libraries

\section{Sponsored by}

Smithsonian

\section{Copyright \& Reuse}

Copyright Status: NOT_IN_COPYRIGHT

This document was created from content at the Biodiversity Heritage Library, the world's largest open access digital library for biodiversity literature and archives. Visit BHL at https://www.biodiversitylibrary.org. 